Paidéia, 2005, 15(32), 345-354

\title{
CONSTRUÇÃO DA CONSCIENTIZAÇÃO SÓCIO-AMBIENTAL: FORMULAÇÕES TEÓ- RICAS PARA O DESENVOLVIMENTO DE MODELOS DE TRABALHO ${ }^{1}$
}

\author{
Susan Mara Lacerda Gumes ${ }^{2}$ \\ Universidade Estadual de Santa Cruz
}

\begin{abstract}
Resumo: Este artigo tem por objetivo discutir questões afeitas à conscientização ambiental. Na resolução das questões ambientais, os grandes desafios estendem-se pela conscientização. A maioria dos modelos de conscientização ambiental adota uma perspectiva unidirecional, que enfatiza em seus conteúdos os aspectos relativos ao ambiente natural, enquanto que, a dinâmica do ecossistema, numa perspectiva moderna, enfatiza uma abordagem integrada entre os aspectos naturais e os culturais. Na busca de formulações que possam colaborar na mitigação deste descompasso, recorre-se a teóricos que propõem, em suas análises, elementos que contribuam para a elaboração de modelos de trabalho capazes de contextualizar e interagir com os aspectos sócio-culturais, considerando a complexidade das relações sócio-ambientais e levando à utilização das forças potenciais do psiquismo humano.
\end{abstract}

Palavras-chave: conscientização ambiental; complexidade; identidade; modernização reflexiva.

\section{SOCIAL-ENVIRONMENTAL CONSCIOUSNESS CONSTRUCTION: THEORETICAL FORMULATIONS FOR THE DEVELOPMENT OF WORK MODELS}

\begin{abstract}
This article aims at discussing environmental consciousness matters. The greatest challenges to face environmental issues have to due with people consciousness. Most of the environmental consciousness models use a unidirectional approach, stressing the natural environment without taking into consideration human dimensions. A modern environmental preoccupation, however, emphasizes an integrated perspective between natural and human dimensions. In order to contribute to reduce this existing gap, this paper aims to work with some theoreticians who bring elements for models of work able to contextualize and integrate social-cultural with natural aspects, taking into consideration the complexity that involves social-environmental relations, emphasizing the use of the potential strengths of the human psyche.
\end{abstract}

Key words: Environmental consciousness; complexity; identity; reflexive modernization.

Introdução: É imprescindível lançar um olhar sobre as questões da modernidade, da globalização, da sustentabilidade, da pós-modernidade, do multiculturalismo, da 'modernidade reflexiva' (Giddens,1991), da ecologização dos sistemas sociais, da incorporação da área ambiental em todas as outras, incluindo a epistemologia, para se compreender a visão de meio ambiente em que se vive (Leff, 2002), que hoje se estabelece numa rede de complexidade maior, bem mais interativa, dependente e 'humanizado' que outrora.

\footnotetext{
${ }_{1}^{1}$ Artigo recebido em 29/09/2004, aceito para publicação em 17/05/2005. ${ }^{2}$ Endereço para correspondência: Susan M. L. Gumes, PRODEMA - Mestrado em Meio Ambiente, UESC - Universidade Estadual de Santa Cruz, Rodovia Ilhéus - Itabuna, Km 16, Ilhéus - Bahia, CEP: 45650-000, E-mail: susanjivan@hotmail.com
}

Giddens (2003) afirma que se vive 'após o fim da natureza', da inesgotabilidade dos recursos, em um mundo incerto, impulsionado pelo risco e que a soberania ocidental, detentora da única razão e verdade inquestionável, cede lugar a um pensamento mais amplo e afinado com a realidade de outras civilizações, antes consideradas atrasadas, primitivas, mas que afirmam seu espaço (Morin, 2001) com o saber simbólico, mitológico e mágico, ao mesmo tempo racional, empírico e técnico. O sistema ambiental atual abarca todas estas questões, sustenta-se na luta de opostos; todo comportamento humano, do mais básico, ao mais elaborado, irá afetar o meio ambiente, uma vez que este está sujeito às atitudes e valores adotados pelos indivíduos, ou seja, as ações huma- 


\section{Susan Mara Lacerda Gumes}

nas, de acordo com o grau de consciência que as conduz, irão determinar os rumos da sobrevivência; é importante, então, que tentativas de promoção da conscientização sócio-ambiental requisitem um tratamento nos moldes da conjuntura sócio-ambiental contemporânea, sendo objetivo deste discorrer sobre estas novas tendências de pensamento, apontando suas necessidades de articulação aos fundamentos que definem as diretrizes de trabalhos de conscientização sócio-ambiental.

Estudos pertinentes à dinâmica social contemporânea e à conscientização ambiental podem ser descritos pelo pensamento sistêmico e complexo. Campos (1999) diz que um sistema é uma unidade possuidora de um espaço interno de organização, coesão e de um esforço externo de adaptação, e que o equilíbrio dinâmico determina seu 'funcionamento ético'. Num sistema ambiental, estas forças seriam a coesão social e suas interações; a organização interna da unidade sistêmica a conserva, e um intercâmbio com outras unidades sistêmicas a transformam, tornando-a dinâmica e mais ampla. Assim, para sobreviver ou manter a capacidade de viver em plenitude, é preciso desenvolver relação de cooperação entre todas as suas partes, pois todas possuem sua importância e função.

Mas, no processo de assimilação de uma estrutura sistêmica, requerem-se bases de pensamento calcadas na complexidade das redes relacionais sociais. Leff (2001) diz que a "sujeição da razão às normas da racionalidade econômico-tecnológica e aos efeitos da racionalização gerada pela razão do poder” (p.40) levam à perpetuação do modelo econômico atual de exploração e à globalização.

Por outro lado, a racionalidade ambiental refere-se a novos princípios éticos, valores culturais e potenciais produtivos necessários às mudanças para a sustentabilidade; trata-se de um saber ambiental que vem da apropriação de um mundo que requer novos direcionamentos, uma civilização com outros sentidos, uma espécie que precisa de espectros de pensamento re/flexivos, criativos, críticos e atuantes. Como ressalta Morin (2002), um saber que possa integrar as disciplinas do conhecimento na explicação de sistemas sócio-ambientais complexos, e, segundo Leff (2001), direcionado a rearticular as interações sociais e naturais, que "excede as ciências ambientais e abre-se ao terreno dos valores éticos, dos conhecimentos práticos e dos saberes tradicionais” ( p.43).

Esta nova forma articulada de pensar e agir diante do meio ambiente é que produz o sentido, dentro da complexidade da modernidade tardia (Giddens,1991) ou da pós-modernidade (Hall,2000), e determina os rumos da conjuntura mundial hodierna.

Um novo direcionamento do desenvolvimento humano e social surge desta crise enfrentada, hoje, pela humanidade; há outra visão do meio ambiente, ampla e integralizadora, e negar os aspectos culturais e humanos nas suas definições significa retirar a natureza no progresso civilizatório, e uma limitação dos paradigmas teóricos. Assim, as concepções de meio ambiente com caráter sistêmico e integrado ligam-se a uma apropriação simbólica da natureza e da cultura, em que os conceitos partem de esquemas mentais, emergindo, organizando e manifestando-se através de símbolos concretos ou abstratos.

Portanto, vislumbra-se uma violência simbólica quando o conceito de ambiente é deturpado ou dissolvido em códigos de poder e manipulação. Na realidade, são as organizações sociais, as manifestações culturais, as decisões políticas, os direcionamentos econômicos que determinam o modo de intervenção no meio ambiente, sua saúde ou deterioração, sua importância ou desconsideração. Aprofundando, inclui-se a dimensão íntima humana na qual se deve "tomar consciência de que, seres humanos, são também natureza, feitos em corpos de água e minérios, ar transformado em sangue, diversidade vegetal e animal transformada em alimentos - e o que acontecer ao solo e à água, ao ar e à biodiversidade, acontecerá ao nosso corpo" (Novaes, 2002, p.19). Consciência esta que será a base para abordar todas as outras, o fio que tece a rede de relações entre os componentes.

Portanto, a concepção deste estudo busca suas bases na dimensão humana dos valores, códigos culturais, formas de conceber o mundo e escolhas dos modos de vida, considerando as possibilidades de construções e reconstruções destes diversificados universos existenciais: inter-relacionados, sistêmicos e complexos. 


\section{Valores humanos e identidade frente à modernização}

O ser humano, como tal, é capaz de ações intencionais e planejadas, definidas por seus valores. A transformação das normas individuais e sociais se torna imprescindível para que a sociedade incorpore demandas emergentes de cada época, tendo seus valores reconhecidos. As questões emergentes neste momento histórico solicitam um re-direcionamento ou incorporação do senso de responsabilidade, virtude e de liberdade.

Liberdade no sentido de desenvolver a autonomia de pensamento e atitude, requerendo responsabilidade para responder pelas ações escolhidas, sem desvinculação da noção de democracia e cidadania. O próprio desenvolvimento, segundo Sen (2000), pode ser visto como um processo de "expandir as liberdades que temos razão para valorizar não só torna nossa vida mais rica e mais desimpedida, mas também permite que sejamos seres sociais mais completos, pondo em prática nossas volições, interagindo com o mundo em que vivemos e influenciando esse mundo" (p.29).

Para Gidddens (2003) as virtudes individuais, sociais ou dos Estados e instituições estão em adequar-se às funções que são chamadas a desempenhar. $\mathrm{O}$ autor denomina as instituições inadequadas a suas funções de 'instituições casca'; parece, então que se poderia falar em 'pessoas casca', 'sociedades casca', para tudo o que mantém natureza indefesa, apática e uma visão distorcida diante dos riscos que ameaçam, num processo de alienação a transferência de poder para outrem. Esta virtude, então, está diretamente ligada à des-alienação ou retomada do poder sobre suas vidas, decisões, modus vivendi, $e$ estilo pessoal (identidade). Como sugere Leff (2002), seria "a re-apropriação social da natureza, da nossa própria natureza”.

Segundo Giddens (2002), a construção da identidade e a tomada de decisões pessoais estão altamente afetadas pelas mudanças ocorridas na nova conjuntura mundial, globalizada, causadora do 'isolamento existencial' e da 'ansiedade existencial'; ele diz que transformações na intimidade e na vida pessoal estão ligadas diretamente ao estabelecimento de amplas conexões sociais. Assim, a conscientização ambiental em prol de um desenvolvimento sus- tentável possui fortes raízes na estruturação pessoal perante questões ambientais globais. Ele salienta ainda que atualmente não é fácil identificar o ser humano pós-moderno, complexo, globalizado, produto da massificação dos meios de comunicação, numa crise existencial que vai além das fronteiras da origem e do destino, e congrega a construção e reconstrução do sentido de identidade e individualidade de forma permanente, o que levou a uma possibilidade muito maior de escolha e liberdade no se definir. Assim, o ser humano de que se trata é aquele que se define e se redefine, dentro de suas escolhas pessoais, com espaço para uma concepção individual e livre de si mesmo.

Mas, Giddens (2002) assinala que a identidade pessoal não está desvinculada dos processos sociais e "o nível de distanciamento tempo-espaço introduzido pela alta modernidade é tão amplo que, pela primeira vez na história humana 'eu' e 'sociedade' estão inter-relacionados num meio global” (p.36); dirse-ia que a conscientização ambiental, com mudanças recorrentes nos modos de percepção e atuação perante o meio, traduz a escolha de um estilo de vida fincada no modelo moral, identificada com as questões existenciais de sobrevivência, com a responsabilidade para com a vida e 'princípios de uma ética ambiental'. O autor fala em 'política de vida' quando da escolha de questões existenciais para a formação da auto-identidade, e alude à inexistência de um sentido pessoal - sensação de vazio interior pelo nada oferecido pela vida - batizando esta ausência de 'isolamento existencial', emergido do alheamento aos recursos morais.

Desta maneira, as escolhas por um estilo de vida interferem diretamente na constituição da autoidentidade e podem influir na formação de novos estilos de vida. A globalização trouxe uma infinidade de opções, que se reportam à reflexão íntima da formação do ser e atuam na realidade local. Assim, global/ pessoal/local estão cada vez mais em interação e interferência mútua, num processo de concepção ontológica reflexiva, obedecendo aos 'mecanismos de desencaixe' (Giddens 2002). O ser humano, ao mesmo tempo cultural e natural, hoje se encontra num universo de construções e reconstruções contínuas, com capacidades reflexivas ampliadas, cada vez mais próximo de ações e auto-formação conscientes e de 


\section{Susan Mara Lacerda Gumes}

maior abertura na elaboração da conscientização ambiental.

\section{A estruturação da consciência segundo António Damásio}

Revisando Damásio (2000), encontram-se elementos importantes na teorização sobre a consciência, que ele denomina uma função biológica crítica, que leva a conhecer sentimentos, dar sentido moral a percepções e ações; ele também atribui escalas a ela: no nível mais simples e elementar, ela permite reconhecer um impulso para permanecer vivos e cultivar o self, no mais complexo ajuda a cultivar o interesse por outras pessoas e aperfeiçoar a arte de viver.

Além desta divisão, Damásio (2000) separa consciência central da ampliada e da moral. Para compreender o que o autor coloca em cada um desses três estágios de consciência, é necessário lançar um olhar sobre suas concepções de imagem e self. As imagens são definidas como "padrões mentais com uma estrutura construída com sinais provenientes de cada uma das modalidades sensoriais - visual, auditiva, olfativa, gustatória e sômato-sensitiva” (p.24), não são estáticas e comunicam aspectos característicos do objeto e da reação frente a ele. A mente seria, então, um processo que apropria as imagens mentais, como resultado da consciência, a partir de quaisquer símbolos concebidos, inclusive sentimentos, tornando-se pensamentos se inter-relacionadas a um fluxo contínuo, e construídas quando da mobilização de objetos ou eventos de fora do cérebro para seu interior e também quando da sua reconstrução pela memória, de dentro para fora.

Neste estudo, este fator é relevante, pois se trata exatamente das construções de elementos imagéticos no interior do self (externos) e da reconstrução (interação de externos e internos já incorporados pela repetição) destes já arraigados que formam o self. As imagens conscientes são as escolhidas pela atenção e acompanham a percepção; a 'janela da mente' é alvo de competição das inúmeras imagens geradas, ficando-se ciente de apenas algumas, mesmo das mantidas na memória. Damásio (2000) acrescenta que a estrutura e propriedades da imagem são construções do cérebro inspiradas por um objeto, isto é, ao invés de repetir o meio ambiente, ele constrói mapas dele, usando seus parâmetros exclusivos e estrutura interna própria, dentro de um 'sistema criativo' - o cérebro. O centro da consciência é o self; ser consciente é ter sentido do self no ato de conhecer. O organismo humano é visto como algo complexo e equipado com capacidade de memória, uma estrutura onde ocorre a dinâmica de formação do self autobiográfico - momentos passageiros de conhecimento em que fatos são "registrados na memória, apropriadamente categorizados e relacionados a outras memórias que concernem tanto o passado como o futuro antevisto” (p.43). Este self é sempre reconstruído pela ampliação da memória e sua remodelagem no decorrer da vida.

Sobre a formação da consciência, Damásio (2000) propõe que ela se inicia como um "sentimento do que acontece quando vemos, ouvimos ou tocamos....que acompanha a produção de qualquer tipo de imagem - visual, auditiva, tátil, visceral - dentro do organismo vivo. O sentimento marca essas imagens como nossas e permite dizer que vemos, ouvimos ou percebemos algo pelo tato” (p.45). O conhecimento de um objeto ou ação atribuída ao self é chamado, portanto, de consciência. O autor distingue estágios de processamento na elaboração da consciência, integrando um continuum: um estado de emoção- consciente ou inconsciente-, de sentimento- representado inconscientemente-, de sentimentotornado consciente. Além disso, ele sugere que a emoção auxilia o raciocínio, especialmente quando se trata de questões pessoais e sociais envolvendo riscos e perigos; tanto ela como os sentimentos seriam as bases para a consciência; o fato de que, quando ela está ausente, as emoções também o estão, comprova a ligação de ambas.

Finalizando, o autor, na mesma obra, propõe a existência de pelo menos três tipos de consciência: 1 . Consciência Central- sentido do self relativo a um momento e lugar. 2. Consciência Ampliada: sentido do self ligado à identidade da pessoa, você ou eu, com situação histórica e temporal, incluindo o passado vivido e o futuro antevisto, sendo as experiências situadas em um contexto mais amplo e intervalo de tempo maior que na Central. 3. Consciência Moral: fundamentada em capacidades consideradas o auge da ascensão humana, como a de sobrepujar as vantagens e desvantagens impostas pelas necessidades de sobrevivência, a percepção crítica, a busca da 
verdade e desejo ou possibilidade em criar normas, ideais e valores regentes do comportamento. A estes tipos de Consciência acrescente-se a existência de um encadeamento; as primeiras funções são da Consciência Central, que, possibilita o self autobiográfico, permite a Ampliada e a Moral. Nota-se que neste encadeamento os graus mais avançados dependem dos primários, mas o funcionamento destes não necessita dos avançados.

\section{Construção da conscientização sócio-ambiental}

A consciência tem sua origem no processo mental do sujeito a partir de reconstruções internas, que dependem das implicações ou disposições sociais para essas construções. É um processo retro-ativo entre indivíduo, consciência pessoal, sociedade consciência social, indivíduo, consciência sócioambiental, que se situa no interior do sujeito, tendo nas imagens provenientes dos objetos (materiais ou imateriais, concretos ou abstratos) e embasadas nos sentimentos, a 'massa' para a sua efetivação. Algumas propriedades, que fazem parte da Consciência Ampliada, definida por Damásio (2000), como a vontade, as mudanças de hábitos, comportamentos, atitudes, decisões voluntárias, auto-aperfeiçoamento, adequação aos valores e demandas sociais, estão situadas na instância última de consciência e dependem da evolução dos processos anteriores mais simples. Assim, para se alcançar este grau de conscientização é necessário se ater aos níveis anteriores. O processo contínuo e hierárquico da consciência, em que a Moral é o seu grau mais elaborado, torna o saber nele engendrado, a compreensão da vida mais apurada e a consciência como um atributo próprio do ser humano - que seria a conscientização.

A concepção de conscientização, no entanto, é melhor trabalhada se for tomada como uma propriedade de atitudes concomitantes entre saber e agir. O conhecimento pode ser adquirido através da educação como transmissão, mas a conscientização seria algo mais complexo que requer a interação entre as várias realidades humanas e o ambiente. $\mathrm{O}$ agir na consciência pode atuar na realidade social, no psíquico ou essencial. Como ação psíquica há a disposição para mudanças, reflexão sobre o sentido e propósito da vida, não-sujeição às condições externas impostas. Como ação ambiental, considera-se o desejo, o querer e a vontade de expansão além das fronteiras da consciência concreta e a busca por valores que dignifiquem o ser humano. $\mathrm{O}$ agir na realidade sócioambiental é também um processo de cidadania, condição posterior da tomada de consciência sócioambiental. A conscientização é anterior à ação, mas numa via de mão dupla em que esta promove aquela. Parece não haver possibilidade de conscientização meramente no nível intelectual, das informações e conhecimento; a sócio-ambiental, de que se fala, é uma ação intermediária internalizada no âmbito pessoal e expressa posteriormente na realidade social. A conscientização sócio-ambiental avançaria além da tomada de consciência em torno de um elemento, seja ele parte da realidade subjetiva ou objetiva do ser, podendo requisitar uma expansão e necessitando de uma abertura, num movimento simultâneo, da sociedade e natureza, do ser humano e filtros culturais, o que caracterizaria a própria expansão da consciência, tendo que a realidade só existe a partir da atribuição de sentido pelo ser e que esse é determinado pelo limite de visão e possibilidade de compreensão dela. Portanto, a conscientização sócio-ambiental, se engendraria neste contexto e, hoje, nos ditames da modernidade tardia.

A conscientização, que considera as variáveis culturais e seus modos de vida, parte da racionalidade ambiental apontada por Leff (2001) e da relação integral, contextualizada, inter-relacionada proposta para o saber por Morin (2002). Seria a consciência crítica, capaz de elaborar novas racionalidades, calcadas na interdisciplinaridade e complexidade, determinando valores éticos de respeito, preservação e qualificação da vida, conduzindo a formas de desenvolvimento e ação construtiva e valorativa de si mesmo, da sociedade e do mundo. Portanto, segundo o pensamento desse autor, a solução básica para as questões enfrentadas hoje em relação ao mundo seria a tomada de consciência, reconhecendo: a Antropológica - 'unidade na diversidade'; A Ecológica 'nossa união consubstancial com a biosfera'; a Cívica - 'convivialidade e solidariedade para com os filhos da terra'. 


\section{Susan Mara Lacerda Gumes}

\section{Reflexão e contextualização no processo de conscientização}

Reflexão, segundo MacNamee e Gergen (1998) significa a inclinação de uma parte sobre si mesma. No nível da consciência, o ser humano seria o único a possuir esta possibilidade, entendendo como o mundo se dobra sobre si mesmo e ele sobre o mundo, desdobramento esse que seria a própria capacidade de reflexão que o ser humano sobre as coisas do mundo externo, do seu mundo interno e interações entre eles.

Atualmente, nos processos sociais da chamada 'modernização reflexiva', Beck (1997) fala de "novo estágio, em que o progresso pode se transformar em destruição, em que um tipo de modernização destrói ou modifica outro... aquela da sociedade industrial” (p.12); então, a edificação do mundo precisa ser repensada, criativamente refletida. Já no sentido subjetivo, esta modernização reflexiva parte da possibilidade da auto-reflexão que traduz indivíduos livres e capazes de construir o próprio futuro, através do pensar sobre valores que podem produzir uma modernidade destrutiva e excessiva. Para Lash (1997) o determinismo cede espaço a uma individuação autônoma relacionada aos ambientes naturais, sociais e psíquicos, conseguida pela capacitação das pessoas com base na conscientização sócio-ambiental. Considerando que a informação e a comunicação estão diretamente relacionadas à possibilidade de capacitação, o papel da mídia, que hoje se coloca acima das consciências, precisa ser revisto, pois ela própria está sujeita às reflexividades da modernidade.

A conscientização reflexiva também é contextualizada. Subjetivamente, a nível primário, as percepções estão inseridas em um contexto e, a depender do grau de adaptação e estruturação do organismo, as imagens são traduzidas diferentemente de um indivíduo para outro, padrão este válido para os interesses e motivações. Sabe-se que a atenção é seletiva e, a depender das expectativas, grau de estimulação e repetição, observam-se certas coisas e ignoram-se outras. Portanto, cada indivíduo possui um contexto e este deve ser considerado na intenção de possibilitar a conscientização; assim, as estimulações devem vir de elementos que façam parte da realidade mais próxima e as expectativas levadas em conta. Mas, de qual realidade aproximada se fala? Da que o indivíduo construiu suas bases valorativas internas, sua capacidade de percepção do mundo, de onde partiram tais valores.

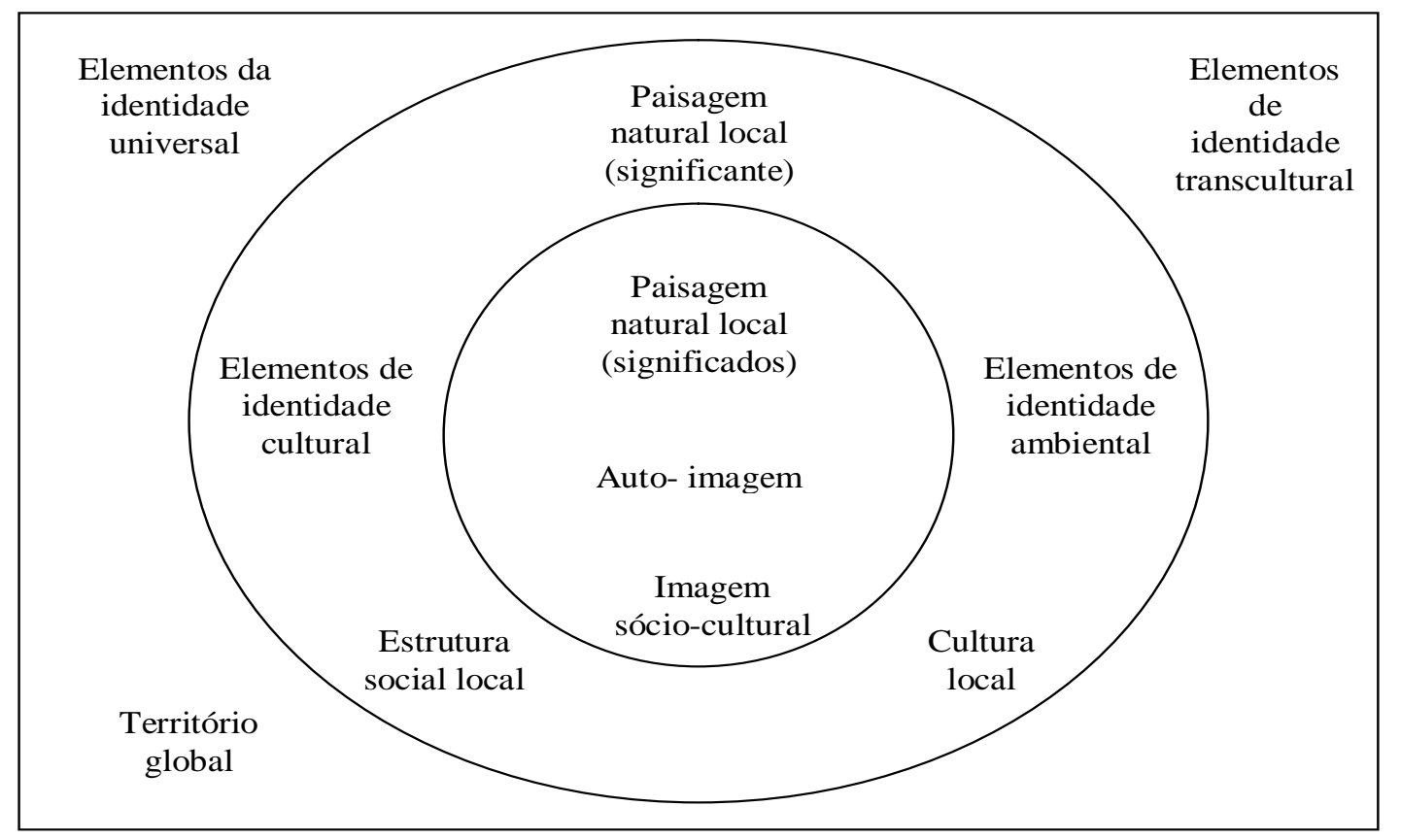

Figura 1: Os contextos que formam e influenciam o indivíduo partem de elementos próximos, substantivos, e se expandem para elementos universais e transculturais. 
Assim, os significados atribuídos a si mesmo, ao ambiente que o cerca e as suas relações sociais, fazem parte do contexto interno e serão considerados em primeira instância. No entanto, eles se iniciam com o reconhecimento e reflexão sobre os elementos culturais, sociais e paisagísticos que possam contribuir para a formação das identidades culturais e ambientais, o que pode ser ampliado para uma percepção mais abrangente, de realidades translocais, identidades universais, coletivas, transculturais. A integração destes elementos, tanto aproximados no espaço, quanto virtualmente, será fundamental no processo reflexivo que indicará os caminhos para a conscientização sócio-ambiental. Para tanto, é preciso desenvolver o pensamento complexo e contextualizado e a prática da interdisciplinaridade nas construções e reconstruções importantes para a conscientização.

\section{Articulação das bases para o desenvolvimento de modelos de trabalho}

Refletindo sobre as congruências do raciocínio apresentado, verifica-se que a construção da conscientização sócio-ambiental passa a ter sentido no momento em que se consegue maior qualidade de vida para dada população. A mudança de uma condição a outra vem pela capacidade dos indivíduos em gerar ações sociais, visando encontrar meios de sobrevivência, prazer e sentido de vida na sua própria estrutura social. Essas ações, por sua vez, necessitam da auto-reflexão da comunidade, quanto à vontade de mudar, de investir no ser humano, fortalecer sua identidade cultural, sem ruptura nos conhecimentos e sabedoria locais, mas possibilitando intercâmbio colaborativo com outras identidades.

Como a identidade na modernidade reflexiva é tratada segundo o pensamento de Giddens (2002) e o self admitido numa visão construcionista do ser, não existe uma localização fixa e fechada na própria cultura ou em si mesmo, mas uma 'linha melódica' em que as identidades se desenvolvem, aninham e afloram todo o tempo em todos os lugares. É este modo de pensar e fazer um trabalho de consciência ambiental que se busca, dentro de um pensar complexo e integrativo, no qual aspectos relativos à consciência são construídos e reconstruídos, são instigadas as adaptações ao pensamento crítico, criativo e reflexi- vo, e ações responsáveis, livres e construtivas, são preservadas.

Neste caso, o processo é de promoção das liberdades substantivas (política e participativa) e de oposição ao que remove as fontes de liberdade, à imposição de valores e à subjugação aos ditames do poder. Tal processo perpassa a educação, ultrapassa-a ao resgatar os valores ambientais e culturais, e implica em recuperar a existência de um saber a ser exposto, liberado; e não incutir a idéia de que o outro não é detentor de conhecimento, de possibilidade de pensamento e ação, de potencialidades endógenas. É desta forma de pensar, que rege o imperialismo, subjuga e desvaloriza o ser humano em todos os níveis, que os trabalhos de conscientização ambiental precisam se libertar.

Para tanto, deve-se: 1- Partir do princípio de que uma organização social necessita de elementos de identidade dirigidos aos valores básicos de sustentabilidade, que precisam ser reforçados, além de terem a capacidade de assimilação dos externos cuja identidade está voltada ao mesmo fim. Segundo Veiga (2005) esses valores básicos de sustentabilidade são os desejos e aspirações humanas consensuais, que se corporificam, por exemplo, em declarações das Nações Unidas, misturados a uma dose de realismo. 2- Perceber a realidade sócio-ambiental e ter a sua imagem reconhecida através de processo de conscientização sócio-ambiental. Se o grupo possui a possibilidade de reconstrução de uma imagem do meio em que vive não afinada aos valores de sustentabilidade, ou, a abertura para elaborar uma 'sustentável', é possível que venha a transformar sua realidade através da percepção apurada e crítica das já existentes, o que deverá estar embasado em práticas sustentáveis, que, aliadas à conscientização sócio-ambiental permanente, reflexiva e contextualizada, poderão levar à construção da sustentabilidade local desejada, que conforme Sachs (Veiga, 2005), definese como harmonização de objetivos sociais, ambientais e econômicos.

\section{Imagens da natureza e da vida para a natureza a para a vida}

Revendo Damásio (2000), observa-se que as imagens são o material utilizado pela consciência, o self é a fonte de sustentação, e o mecanismo de ela- 


\section{Susan Mara Lacerda Gumes}

boração é o cérebro. Assim, para que a consciência cumpra seu papel na escala de evolução humana, ela precisa ser capaz de acoplar, traduzir e memorizar imagens de origem sensorial e conceitual. Dependendo do tipo de imagem absorvido pelas janelas da mente, ou melhor, das que mereceram atenção, o self se estrutura com bases ecológicas ou não. A reflexão, o diálogo e a expressão são bases para a seleção e crítica das imagens adotadas e também a forma de resgate do material ecológico do inconsciente no interior do self.

Tratando da utilização de práticas ecológicas em um contexto grupal, com o intuito de desenvolver a consciência voltada para tais questões, necessitase de um instrumento que possa, ao mesmo tempo, ter como objetivo direcionar imagens do universo material ou imaterial, sensorial ou conceitual, saindo do interior do self para fora ou do meio externo para o interior do self. Integrando esta dinâmica, enfatizase a possibilidade de atentar e permitir construções e reconstruções com conteúdo imagético ecológico (sustentável).

Assim como o diálogo, a reflexão e o silêncio, além de elementos do universo artístico, poderão facilitar a entrada no simbólico e o desenvolvimento de potenciais forças de consciência ambiental, que, neste caso, estarão relacionadas ao meio ambiente natural ou social - da natureza e da vida, tanto advindas desse meio quanto direcionadas a ele.

\section{Imagens sensoriais e conceituais}

A consciência se estrutura a partir de imagens sensoriais e conceituais; ambiente é conceito, e cada um possui o seu, sendo que o símbolo faz parte dele, determinando o que se pensa sobre, como se vê e se sente. Segundo Tuan (1980) e Ostrower (1987), o símbolo tem o poder de sugerir um todo ou a interpretação de um objeto quando projeta significados e traz à consciência um circuito de fenômenos relacionados entre si, que traduzem momentos dinâmicos do self, através da configuração de uma matéria física ou psíquica articulada a aspectos espaciais e temporais. É preciso entender cada conceito para contextualizar um no outro - o que se consegue identificar como próprio e o que está subjacente a isto. Quando as pessoas estão alienadas do seu contexto social ou ambiental, os conceitos destes temas e a noção do próprio meio se tornam algo muito abstrato, distanciado, até, da sua realidade.

Os símbolos, neste caso, podem proceder de um todo, ou de significados não alinhados com o real e necessidades pessoais, como os elaborados pela mídia - comportamentos, padrões corporais, estilos de vida - que estão distantes das possibilidades humanas e naturais, causando insatisfações em relação ao vivencial e circunstancial que nunca atingirão o modelo idealizado imposto. Ocorre, entretanto, que os problemas sociais e ambientais que os símbolos da mídia oferecem ficam próximos aos fictícios que ela cria, e passam a ser interpretados, também, como ficção, colocando as soluções e problemas reais no 'desfecho da próxima novela’. Logo, para que um conceito possa ser vivenciado e compreendido em sua extensão mais concreta, é preciso contextualizá-lo, trazê-lo à realidade, para que haja reflexão, e dela a conscientização e as ações necessárias.

Deste modo, a percepção - estímulos externos registrados - forma imagens, que geram conceitos pela consciência, que determinam valores, que formam a visão de mundo, e esta o modo de vida, incorrendo assim em atitudes e ações diante dela.

A depender do grau de consciência na estruturação das imagens e escolha dos valores, temse seres humanos com maior ou menor grau de consciência, poder de escolha, capacidade de reflexão, intervenção social, atividade ou passividade. Claro que esse grau de consciência está determinado por predisposições pessoais, influências familiares, circunstâncias sociais; mas, grande parte desse material poderá ser re-elaborado, principalmente em se tratando de integrantes da 'modernidade reflexiva'. Partindo deste princípio, tudo o que se deseja utilizar para a conscientização precisa ser contextualizado e identificado dentro da realidade com que se deseja trabalhar.

\section{Considerações finais}

As formulações teóricas analisadas possuem o objetivo de contribuir na elaboração de modelos de trabalho de conscientização ambiental que congreguem valores afinados com a realidade, necessidades e limites da modernidade para que sejam ser efetivos em suas ações. Para tanto, tais modelos solicitam componentes gerais como: a) sua fundamentação - que orienta a elaboração de princípios 
norteadores do trabalho, e seus conteúdos, segundo os princípios norteadores; b) os métodos utilizados escolhidos seguindo os princípios e necessidades de aplicação dos conteúdos; c) as técnicas usadas selecionadas de acordo com as necessidades do método; d) os recursos devidos. Os fundamentos podem servir como embasamento na elaboração de quaisquer modelos de trabalho de conscientização (ou educação) ambiental e, até mesmo, na criação de métodos específicos nessa mesma área.

Sintetizando alguns dos fundamentos, recorrese ao que Rist (2002) denominou de a 'invenção do desenvolvimento', proclamada logo após a $2^{\mathrm{a}}$ guerra mundial, e lançada pelos Estados Unidos a partir do ideal de ajuda técnica aos países desfavorecidos. Assim, o desenvolvimento é posto como um bem comum (sua implantação necessitaria ser conforme as normas estabelecidas pelos países mais poderosos do mundo), definindo o subdesenvolvimento como um estado de falta, alienação e incapacidade, sendo a técnica um valor neutro e única resposta possível. Isto levou à falha na autodeterminação e reconhecimento dos próprios valores, à perda da identidade e independência econômica dos países ditos 'subdesenvolvidos'. Então, o intuito da conscientização ambiental, para os povos dos países subjugados, deveria possuir, em suas bases, o princípio de recuperação do poder de autodeterminação, das vias de desenvolvimento e dos modos de vida.

Assumindo este como princípio básico, tem-se que:

- A autodeterminação requer possibilidade de pensamento e ação, portanto, liberdade (Sen, 2000), que pode ser alcançada com a promoção do debate livre, das transparências ideológicas das instituições, da análise e escolha da população (promoção de políticas públicas). Portanto, um dos princípios decorrentes da autodeterminação é a liberdade de expressão e de ação, devendo os trabalhos de conscientização ambiental vislumbrar a promoção de políticas públicas. Neste sentido, enfatizam-se os pensamentos reflexivos que, em seu âmago, são criativos (encontrar soluções para as questões), críticos (reconhecer os problemas, limitações e possibilidades) e atuantes (tomar decisões e concretizar ações). Portanto, três princípios regerão os trabalhos de conscientização ambiental: 1-Autodetermi- nação; 2-Liberdade de expressão e ação; 3Reflexividade.

Com base nesses princípios e em noções de complexidade dos sistemas humanos, naturais e culturais, de tratamento interdisciplinar dos conteúdos e contextualização das diversas realidades, selecionaram-se alguns elementos norteadores para escolha dos conteúdos, métodos e técnicas, utilizados na elaboração do modelo de trabalho pesquisado.

Conteúdos - segundo dois aspectos: 1- A realidade interna e externa do indivíduo, considerando o mundo real e concreto de cada um, a noção orgânica, os sentidos, as realidades emocional, mental, física, psíquica, familiar e social ${ }^{3}$. 2- Os aspectos sócio-culturais, que se relacionam aos valores (materiais e imateriais), modos de agir, crenças, modos de pensar, vivências familiares e com o contexto do qual a pessoa faz parte, convergindo para o pensar sobre sua própria cultura ${ }^{4}$.

Metodologia e técnicas adotadas - parte-se do caráter processual na formação da consciência (Damásio, 2000), e daí torna-se possível traçar um roteiro em que se organizam os conteúdos. 1 . Inicialmente, determinam-se as etapas que possuem uma dinâmica processual crescente, incluindo apresentação do grupo, do trabalho, do tema, reflexão sobre este, alongamento corporal, desbloqueio (físico, mental e emocional). A seguir inserem-se sequencialmete as fases no contexto, mobilização, desbloqueio, centramento, sensibilização, conscientização, integração e, finalmente, a expansão. 2- Diretrizes para a inclusão de cada tema e sub-tema trabalhado, como percepção, conscientização e atuação, tendo sido selecionados: resgate das memórias, auto-percepção, percepção ambiental local, global, conscientização sócio-ambiental e atuação sócioambiental. A partir de cada tema incluem-se os subtemas - definidos de acordo com características e

\footnotetext{
3 Acredita-se ser mais fácil, por exemplo, iniciar a sensibilização e conscientização ambiental com os habitantes de centros urbanos através de materiais reciclados, que façam parte do dia-a-dia, do que com noções distanciadas de natureza. Pode-se introduzir, no entanto, elementos advindos de contextos naturais universais, como os próprios da identidade universal: ritmos naturais, memórias ontogenéticas, entre outros.

${ }^{4}$ Nesta categoria, acentua-se a inclusão de músicas e danças regionais e do folclore nacional, memórias de infância e símbolos da mitologia regional. Porém, além dos contextos localizados adicionam-se os contextos transculturais e universais.
} 


\section{Susan Mara Lacerda Gumes}

objetivos de cada trabalho e público. 3 - Finalmente, a opção pelas técnicas para trabalhar os temas, tomando por base a Musicoterapia, a Arteterapia e a Ecopsicologia: debates, reflexão crítica, reflexão imagética e conceitual, imersão ambiental, visualização criativa, movimentação corporal, relaxamento, recepção simbólica, escuta e percepção ambiental, re-criação ritualística, treinamento da sensibilização, criatividade e expressividade, significação e re-significação ambiental.

Conclui-se ser possível assimilar elementos complexos que envolvem o funcionamento do sistema sócio-ambiental contemporâneo e aplicá-los com objetividade. Há uma longa caminhada, nas vias das especulações científicas, para encontrar soluções mais eficientes na resolução de questões ambientais; através da análise de novas formas de gerar conscienti-zação ambiental, espera-se colaborar para o alcance desta meta, avançando, assim, em ressonância com os rumos do deslindamento de um novo estágio de desenvolvimento humano, em prol da manutenção da vida.

\section{Referências Bibliográficas}

Beck, U. (1997). A reinvenção da política: rumo a uma teoria da modernização reflexiva. Em U.Beck, A.Giddens, \& S. Lash, (Orgs.). Modernização reflexiva (pp.11-71). São Paulo: UNESP.

Campos, E. P. (1999). Sociedade e estresse. Edição especial do JBM, 78, 18-21.

Damásio, A. (2000). O mistério da consciência. São Paulo: Companhia das Letras.

Giddens, A. (1991). As conseqüências da modernidade. São Paulo: UNESP.

Giddens, A. (2002). Modernidade e identidade. Rio de Janeiro: Jorge Zahar.

Giddens, A. (2003). Mundo em descontrole. Rio de Janeiro: Record.

Hall, S. (2000). A identidade cultural na pósmodernidade. São Paulo: DP\&A.

Lash, S.(1997). A reflexividade e seus duplos: estrutura, estética, comunidade. Em U.Beck, A.Giddens, \& S.Lash, (Orgs). Modernização reflexiva. (pp. 135-206). São Paulo: UNESP.
Leff, E. (2001). Saber ambiental. Rio de Janeiro: Vozes.

Leff, E. (2002). Epistemologia ambiental. São Paulo: Cortez Editora.

McNamee, S. \& Gergen, K. (1995). A terapia como construção social. Porto Alegre: Artes Médicas.

Morin, E. (2001). Saberes globais e saberes locais: O olhar transdisciplinar. Rio de Janeiro: Garamond.

Morin, E. (2002). Educação e complexidade: os sete saberes e outros ensaios. São Paulo: Cortez.

Morin, E. (2002). Os sete saberes necessários à educação do futuro. São Paulo: Cortez.

Novaes, W. (2002). A década do impasse. São Paulo: Estação Liberdade/ISA.

Ostrower, F. (1987). Criatividade e processos de criação. Petrópolis: Vozes.

Rist, G. (2002). L'invention du développement. Revue L'écologiste, 6, 19-22.

Sen, A. (2000). Desenvolvimento como liberdade. São Paulo: Companhia das Letras.

Tuan, Yi-F. (1980). Topofilia: um estudo da percepção, atitudes e valores do meio ambiente. São Paulo: DIFEL.

Veiga, J. E. (2005). Desenvolvimento sustentável: o desafio do século XXI. Rio de Janeiro: Garamond.

Este artigo procede de exame parcial do capítulo de revisão de literatura da dissertação de mestrado 'Construções e reconstruções em modelo de trabalho de conscientização sócio-ambiental'.

Apoio: CAPES. 